\title{
O estágio de docência universitária: o uso do blog como possibilidade didático-metodológica
}

\author{
Andrieli Dal Pizzol ${ }^{1}$ \\ Jamile Santinello² \\ Eliziane de Fátima Alvaristo ${ }^{3}$
}

\section{Resumo}

O presente estudo teve como objetivo apresentar a relação do estágio de docência no Ensino Superior no uso do blog como possibilidade didática. Nesse viés, evidencia-se a relação estabelecida entre o estágio com a disciplina de Educação e Tecnologia, da Universidade Estadual do Centro-Oeste - UNICENTRO localizada no interior do estado do Paraná. O estudo utilizou-se de uma abordagem qualitativa apoiada nos estudos de Bardin (2016). Assim, o estudo demostrou que a utilização do blog como ferramenta tecnológica educacional contempla a inserção da tecnologia em ambientes educacionais e que seu uso deve estar alinhado com as necessidades dos sujeitos inseridos no ambiente escolar e em consonância com o currículo formativo.

Palavras-chave: Formação de Professores; Ensino-Aprendizagem; Interação.

\section{The university teaching internship: the use of the blog as a didactic-methodological possibility}

\section{Abstract}

This study aimed to present the relationship between the teaching internship in Higher Education in the use of the blog as a didactic possibility. In this way, it evidences the relationship established between the internship and the discipline of Education and Technology, from the State University of the Midwest - UNICENTRO, located in the interior of the state of Paraná. The study used a qualitative approach supported by the studies of Bardin (2016). Thus, the study showed that the use of the blog as an educational technological tool contemplates the insertion of technology in educational environments and that its use must be aligned with the needs of the subjects inserted in the school environment and in line with the training curriculum.

Keywords: Teacher Training; Teaching-Learning; Interaction.

\section{Introdução}

A expansão da internet e dos meios digitais tem proporcionado grandes avanços no desenvolvimento de atividades educacionais, sobretudo com a exploração de ferramentas que incrementam as ações pedagógicas em diferentes contextos. Em um mundo conectado e globalizado, onde a internet é parte integrante na rotina da maioria da população, a sua utilização

\footnotetext{
${ }^{1}$ Universidade Estadual do Centro-Oeste - UNICENTRO, Guarapuava-PR, e-mail: andrielidp@gmail.com

2 Universidade Estadual do Centro-Oeste - UNICENTRO, Guarapuava-PR, e-mail: jamilesantinello@gmail.com

${ }^{3}$ Universidade Estadual do Centro-Oeste - UNICENTRO, Guarapuava-PR, e-mail: elizianeclaro@hotmail.com
} 
frente a formação de futuros professores não poderia ser deixada de lado (MORAN, 2013).

Nesse interim, utilizou-se da prática do Estágio em Docência no Ensino Superior para a realização desse estudo, atividade destinada aos acadêmicos de cursos de Pós-Graduação em nível de Mestrado e Doutorado no país, especificamente o Programa de Pós-Graduação em Educação/PPGE da Universidade Estadual do Centro-Oeste/UNICENTRO, localizada no município de Guarapuava/PR.

O estágio de docência foi realizado durante o terceiro e quarto período do curso de Pedagogia, da instituição supracitada, na disciplina de Educação e Tecnologias - anual, com carga horária de 68 horas. Durante a prática de observação estágio, para aplicação da prática docente pela estagiária, foi solicitado pela docente responsável pela disciplina a utilização do blog como ferramenta educacional, uma vez que, durante o desenvolvimento das aulas, os acadêmicos assinalaram não possuírem familiaridade com a ferramenta e nem como poderia ser utilizado em sua futura prática pedagógica.

O estudo subdivide-se em quatro tópicos que tratam, respectivamente, sobre: as contribuições das ferramentas online e offline como possibilidade didática; um olhar para o ensino híbrido; o contexto educacional da disciplina de Educação e Tecnologias, e; as práticas do estágio de docência: aplicação e uso do blog como possibilidade de ensino.

Esta análise de conteúdos por meio do estudo de caso e pesquisa qualitativa é apoiada nos estudos de Bardin (2016). Justifica-se essa metodologia devido ao fato de a pesquisa qualitativa observar as relações sociais e os diferentes espaços do dia a dia, e em especial o cotidiano escolar, ao passo que o estudo de caso ganha destaque por poder organizar o método de pesquisa segundo cada polo cronológico.

Para Bardin (2016), as diferentes fases de análise de conteúdo estão organizadas em volta de três polos cronológicos, sendo eles a pré-análise, a exploração do material e, por fim, o tratamento dos resultados, a inferência e a interpretação. No primeiro, tem-se a organização das ideias e do planejamento; já a exploração do material está relacionada com a aplicação propriamente dita do que foi planejado no passo anterior. Ao chegar no terceiro polo cronológico, trabalha-se com os resultados de forma com que eles se tornem significativos.

É importante ressaltar que a escolha do estágio de docência para a utilização da ferramenta, pois, de acordo Pimenta e Lima (2018), trata-se um espaço de pesquisa em que 
ocorre a concretização da identidade docente e apropriação do conhecimento pedagógico, levando em consideração o processo como um todo. Assim, a prática do estágio está relacionada também a transformação do sujeito frente às ações diárias de convívio e construção das relações entre a teoria e prática.

O blog como ferramenta colaborativa, permite a construção de conteúdos e conhecimentos de maneira participativa, articulando com o uso de tecnologias em espaços escolares. Para Moran (2013), a possibilidade de os acadêmicos explorarem, expressarem e fazer com que suas ideias e pesquisas tornem-se visíveis ao número maior de pessoas, faz com que o trabalho se torne mais significativo.

\section{As contribuições das ferramentas online e offline como possibilidade didática}

As ferramentas educacionais caracterizam-se por serem utilizadas no ambiente escolar, sejam online, por meio do uso da internet, ou offline, com softwares instalados em computadores, notebooks e demais dispositivos. Sobre o assunto, Primo $(2001$, p.8) destaca que “muitas são as ferramentas disponíveis para a mediação em ambientes de educação através do computador", indo desde editores de textos e calculadoras, até aos aplicativos, softwares, programas, vídeos e redes sociais.

De acordo com Teixeira e Brandão (2003), a utilização de computadores em sala de aula só terá sentido quando os professores compreenderem que ele auxilia no desenvolvimento de atividades pedagógicas, utilizados como meio de colaboração para o processo de ensinoaprendizagem, tornando a prática docente mais dinâmica, ativa e colaborativa.

O processo de informatização é relativamente recente e a sua utilização no ambiente educacional também parte da promoção pelas escolas, assim, "uma das formas de se alcançar esse objetivo é a instituição reconhecer que o uso da tecnologia potencializa a ação de todos os sujeitos e pode estreitar os laços existentes entre professores, alunos, gestores e pais" (SUNAGA; CARVALHO, 2015, p.141).

O uso dessas ferramentas, sejam online ou offline, fomentam a curiosidade dos acadêmicos, contribuindo para o processo de ensino-aprendizagem e gerando um engajamento de forma natural. Desse modo, a interação desenvolvida por meio das tecnologias no âmbito 
educacional são diferenciais para o progresso da prática docente, tornando-se primordial pensar os métodos e estratégias educativas para essa inserção:

Quer-se enfatizar a interação como elemento catalisador para a construção do conhecimento. Não uma interação determinista, de objetivos fechados, com desenrolar previsto, por antecedência. Mas uma relação que valoriza o diálogo, a negociação, a cooperação, enfim, a transformação mútua (PRIMO, 2001, p.15).

Nesse sentido, compreende-se que o desenvolvimento de ações por meio da interação de ferramentas educacionais deve-se pautar em objetivos pré-determinados que possibilitem uma interação saudável do uso dos dispositivos e suas potencialidades, proporcionando o diálogo, o crescimento e o conhecimento entre os aprendizes (PRIMO, 2001). O professor ao planejar aulas com uso de tecnologias, aplicativos e softwares verificar a relevância que estas ferramentas possuem no contexto como forma de melhorar o processo de ensino e a aprendizagem.

\section{Um olhar para o ensino híbrido}

O ensino híbrido combina atividades presenciais por meio das Tecnologias Digitais de Informação (TDIC), em que o foco de aprendizagem é centrado no aluno e não na simples transmissão da informação por parte do professor (BACICH; MORAN, 2018).

Seria interessante que todas as instituições escolares tivessem a possibilidade de possuir computadores e acesso à internet, mas, devido a questão de infraestrutura, localização e de verbas, essa realidade mostra-se distante. Para aquelas onde esse acesso, mesmo que limitado, é possível, existem diversas ações e organizações que podem ser feitas para desenvolver atividades que contemplem o uso das tecnologias, pois "um diferencial do ensino híbrido é que não é necessário que todos os alunos estejam ao mesmo tempo nas estações on-line. Assim, não há necessidade de muitos dispositivos com acesso à internet para que a aula aconteça" (SUNAGA; CARVALHO, 2015, p.145).

Destaca-se também a possibilidade de utilização de dispositivos móveis no ambiente escolar, como os smartphones, como ferramentas a serem utilizadas com viés pedagógico, juntamente com computadores e notebooks, ampliando e possibilitando uma melhoria na 
aprendizagem e interação dos acadêmicos com os conteúdos desenvolvidos dentro e fora da sala de aula. Nesse interim, Chiofi e Oliveira $(2014$, p.330) destacam que "[...] a tecnologia ao seu alcance como ferramenta pedagógica contribui didaticamente para obter maior atenção, e consequentemente, o uso adequado e coerente com o conhecimento escolar e o próprio currículo".

Estes aparelhos podem ampliar o acesso a conteúdo, criando comunidades de aprendizagem onde pessoas que estão a quilômetros de distância podem discutir e debater sobre o mesmo assunto. A partir disso, Chiofi e Oliveira (2014, p.334) reiteram que,

[...] é fato de que o conhecimento e o domínio do saber são de responsabilidade do professor, entretanto, a tecnologia poderá ser uma ferramenta didática quando na transposição didática desse saber. Através da técnica, o conhecimento poderá melhor se adequar ao perfil dos nossos alunos na contemporaneidade (sociedade marcada pelos avanços técnicos).

Portanto, deve-se levar em consideração a realidade de cada instituição de ensino, como ocorre a apropriação dessas tecnologias e qual a melhor forma de inseri-las no ambiente educacional, potencializando e contribuindo com o processo de ensino-aprendizagem.

Ao observar o uso dessas ferramentas tecnológicas educacionais por parte dos acadêmicos, torna-se necessário que o professor planeje as atividades para que a utilização desses dispositivos e suas ferramentas fomentem o conhecimento. Sem um planejamento prévio sobre onde se quer chegar, a essa metodologia deixará a desejar, entretanto, "a tecnologia se bem utilizada pode beneficiar o trabalho pedagógico na escola, com propostas dinamizadoras do conhecimento e, para, além disso, como processo de comunicação e construção do saber escolar por alunos e professores" (CHIOFI; OLIVEIRA, 2014, p.334).

A construção, comunicação e interação entre alunos, professores e comunidade escolar, apresenta-se como uma nova maneira de pensar em educação, sendo ela transformadora e potencializadora de ações que possibilitem a interação entre todos os sujeitos envolvidos no processo educacional, visando o seu pleno desenvolvimento.

Além disso, é possível fazer uso desses recursos em duplas ou grupos, bem como promover momentos online, em casa ou em lan houses, caso as escolas não disponham de nenhum tipo de recurso tecnológico, garantindo assim a mistura do ensino virtual com o offline, 
característica do ensino híbrido (SUNAGA; CARVALHO, 2015, p.145). Por outro lado, este método de ensino demanda por parte do aluno um compromisso muito maior, sendo necessário verificar a disponibilidade da instituição escolar e de seus alunos para adequar as propostas com o uso de ferramentas tecnológicas.

Sobre o assunto, Moran (2013) destaca que o digital dentro do espaço escolar será tão importante no processo de ensino-aprendizagem como o espaço da sala de aula é, e que "na sociedade conectada, todos estamos reaprendendo a conhecer, a nos comunicar, a ensinar; reaprendendo a integrar o humano e o tecnológico; a integrar o individual, o grupal e o social" (MORAN, 2013, p.68). Portanto, é preciso quebrar as barreiras entre o mundo físico e o digital, interagir e integrar o uso das tecnologias e suas ferramentas como fonte de possibilidades alternativas de fazer uma educação diferente, buscando proporcionar novas experiências e aprendizagens e potencializando a participação dos alunos junto de seus professores.

Sunaga e Carvalho (2015) afirmam que o foco principal da utilização de uma ferramenta educacional não pode dar-se por si própria, é essencial que os docentes verifiquem nesses recursos seus benefícios e se a utilização dela atenderá os objetivos propostos para a determinada aula.

\section{O contexto educacional da disciplina de Educação e Tecnologias}

O processo de ensino na Universidade Estadual do Centro-Oeste/UNICENTRO no curso de Pedagogia oferta, em sua grade curricular, a disciplina de Educação e Tecnologias, considerada bimodal, isto é, possui em sua carga horária parte do ensino presencial (80\%) e a distância (20\%). A disciplina tem como objetivo "analisar o contexto da relação entre educação e tecnologias na prática pedagógica do cotidiano escolar" (UNICENTRO, 2019, s. p.). Dessa maneira, observa-se que a disciplina vem de encontro com os atuais debates a respeito da inserção das tecnologias no cotidiano escolar.

Nessa direção, a ementa da disciplina apresenta pontos essenciais de discussão sobre a:

[...] relação entre educação e tecnologias na prática pedagógica do cotidiano escolar. Processos didáticos e metodológicos com a utilização das tecnologias da informação e comunicação na educação presencial e a distância. Técnicas de 
produção e publicação de objetos de aprendizagem e recursos de aprendizagem abertos (UNICENTRO, 2019, s. p.).

Os recursos de aprendizagem abertos têm como intuito possibilitar o desenvolvimento da tríade ensino, aprendizagem e pesquisa, pois, utilizam-se de materiais digitais educacionais, disponibilizados de forma gratuita para a comunidade acadêmica em geral.

A metodologia aplicada na disciplina aborda dinâmicas, em grupos e individuais, desenvolvidas em laboratório de informática disponíveis na universidade, com o uso de celulares dos próprios acadêmicos, por meio de aplicativos e softwares. Os canais de comunicação são as videoconferências, redes sociais e aplicativos de comunicação, como WhatsApp, Ambiente Virtual de Aprendizagem - AVA/Moodle ${ }^{4}$ e blogs, promovendo a socialização e a troca de informação sobre o conteúdo da disciplina.

Como salienta Moran (2013, p.13), "as tecnologias móveis, que chegam às mãos de alunos e professores, trazem desafios imensos de como organizar esses processos de forma interessante, atraente e eficiente dentro e fora da sala de aula, aproveitando o melhor de cada ambiente, presencial e digital".

A disciplina possibilita ao aluno uma construção coletiva de conteúdos e conceitos a respeito da inserção das tecnologias em âmbito educacional, promovendo discussões e debates sobre como essa integração pode auxiliar no desenvolvimento de ensino e aprendizagem dos alunos, de diversos níveis e modalidades de ensino.

\section{As práticas do estágio de docência: aplicação e uso do blog como possibilidade de ensino}

A prática do estágio de docência desenvolvido no curso de Pós-Graduação em Educação da Unicentro faz parte do currículo do programa, sendo uma atividade obrigatória direcionada aos bolsistas de instituições de fomento e para os demais, conta como complementação da carga horária.

\footnotetext{
4 "O desenvolvimento do ambiente Moodle foi realizado pelo australiano Martin Dougiamas que, com sua formação acadêmica em Informática e educação, conseguiu unir modernas técnicas e recursos computacionais de desenvolvimento com a pedagogia do construcionismo social, resultando em um ambiente virtual focado na aprendizagem". FERREIRA, J. L. Moodle: um espaço de interação e aprendizagem. In: COSTA, M. L. F.; ZANATTA, R. M. (orgs.). Educação a distância no Brasil: aspectos históricos, legais, políticos e metodológicos. 3. ed. Maringá: Eduem, 2014, p.55.
} 
Para desenvolver o estágio na instituição, o acadêmico deve preencher um requerimento de realização, e deve elaborar um plano de atividades de acordo com o plano de ensino da disciplina, em consonância com o do professor responsável pela disciplina. Após passar pela reunião do colegiado, o discente inicia o estágio, seguindo as normas contidas no regimento do PPGE.

Assim como ocorre nos estágios de graduação no ensino da Educação Básica, a realização do estágio de docência no ensino superior, além de cumprir créditos, possibilita aos discentes terem contato com o processo de ser docente no Ensino Superior, como explícito no art. 18 da Portaria 76/2010 “[...] o estágio de docência é parte integrante da formação do pósgraduando, objetivando a preparação para a docência, e a qualificação do ensino de graduação sendo obrigatório para todos os bolsistas do Programa de Demanda Social [...]"(BRASIL, 2010, p.32).

O presente estudo abordou uma prática realizada durante o estágio de docência na graduação no curso de Pedagogia da Unicentro, campus Santa-Cruz, no ano de 2019. A experiência vivenciada contou com a participação das turmas do 20 ano, matutino e noturno, totalizando 34 acadêmicos envolvidos.

Em consonância com o plano de ensino da disciplina de Educação e Tecnologias, estabelecido em comum acordo com a professora responsável, foi desenvolvido o estudo e aplicação do uso de blog como uma possibilidade de prática pedagógica. Sendo assim, estaria o blog desatualizado para a era tecnológica?

Em um primeiro momento, como introdução da temática aos acadêmicos, questionou-se qual era o conhecimento e familiaridade deles com a ferramenta, e alguns demonstraram não ter conhecimentos e outros não achavam relevante o seu uso, por considerarem algo ultrapassado.

Desse modo, optou-se por apresentar o blog aos acadêmicos e suas possibilidades para o processo de ensino, evidenciando os seus conceitos e significados e exemplificando como pode ocorrer a sua utilização dentro da sala de aula.

Para Gomes (2005), o termo blog é uma abreviatura do termo descrito em língua inglesa weblog, com registro da primeira utilização por volta de 1997 nos EUA, por Jorn Barger. Desde a sua configuração inicial, o blog, é uma página que precisa ser atualizada frequentemente por 
meio da submissão de mensagens de textos, vídeos, fotos e arquivos de áudio. Assim, a sua utilização vai de encontro com situações mais específicas, como por exemplo, para uma turma, uma disciplina, para apresentar um determinado conteúdo, dentre outras.

Para clarificar a questão sobre o uso do blog com os acadêmicos, foi apresentado o blog ${ }^{5}$ desenvolvido por um professor, como mostra a Figura 1:

Figura 1 - Print Screen Blog do Professor Claudinei

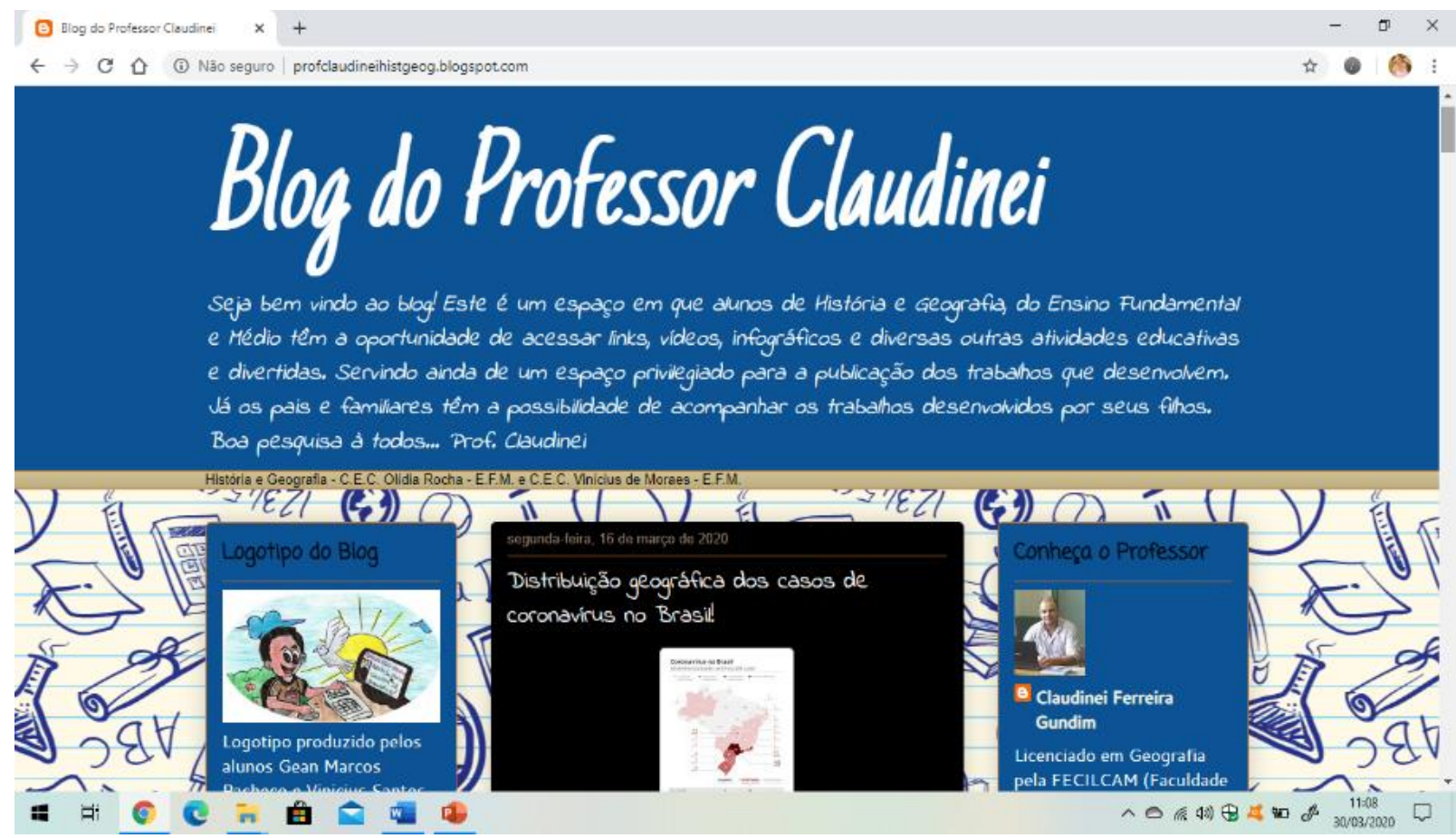

Fonte: Autores.

O blog do professor Claudinei foi desenvolvido para a realização de práticas nas disciplinas de História e Geografia, e a ferramenta é utilizada desde o ano de 2011, em escolas do campo do município de Nova Tebas/PR, na rede pública de ensino.

Após os acadêmicos navegarem pelo blog, foi possível perceber a satisfação com a ferramenta, pois compreenderam que ela auxilia no processo de ensino. O recurso supracitado utilizado pelo professor Claudinei em uma escola do campo torna-se um diferencial, levando em consideração que muitas delas não possuem acesso as tecnologias digitais pela falta de recursos

\footnotetext{
${ }^{5}$ Disponível em: http://profclaudineihistgeog.blogspot.com/.
} 
e infraestrutura e que práticas desse cunho tendem a potencializar o processo de ensino e aprendizagem em instituições com pouco acesso.

Para Moran (2013, p.42-43) o blog permite:

[...] a atualização constante da informação, pelo professor e pelos alunos, favorece a construção de projetos e pesquisas, individuais e em grupo, e a divulgação de trabalhos. Possibilitam que os docentes acompanhem o progresso de cada aluno, nas ideias e na exposição escrita destas. Com a crescente utilização de imagens, sons e vídeos, os videologs são cada vez mais importantes na educação e se integram a outras ferramentas tecnológicas de gestão pedagógica.

Após a compreensão dos acadêmicos sobre a importância do blog e as possibilidades para integrar o processo de ensino foi proposto que, eles criassem um blog para conhecer a ferramenta. Para dar sequência à proposta, foi trabalhada uma leitura curta com os alunos, de um texto publicado no ano de $2005^{6}$, em que considerava o blog como uma ferramenta colaborativa para o processo de ensino-aprendizagem e apesar, de ser considerado um texto antigo, traz consigo, uma reflexão pertinente para os dias atuais, como "[...] há blogs que se constituem como portfólios digitais do trabalho escolar realizado e blogs que funcionam como espaço de representação e presença na Web de escolas, departamentos ou associações de estudantes"(GOMES, 2005, p.311).

Durante a atividade, os acadêmicos verificaram as funcionalidades da ferramenta, criando uma página e realizando uma publicação no seu próprio blog, e, a partir desse momento, foi possível verificar o interesse no seu uso na prática docente.

Posteriormente à exploração do blog, foi entregue aos acadêmicos um questionário simples, com duas questões a respeito do conteúdo trabalho em sala de aula. Foram recebidos 34 questionários, em que os discentes serão identificados com a letra $A$, acrescido de um numeral para manter o sigilo das suas identidades.

\footnotetext{
6 GOMES, J. M. Blogs: um recurso e uma estratégia pedagógica. Disponível em: https://repositorium.sdum.uminho.pt/bitstream/1822/4499/1/Blogs-final.pdf.
}

Periódico Horizontes - USF - Itatiba, SP - Brasil - e021009 
Quadro 1. Questionário entregue aos acadêmicos

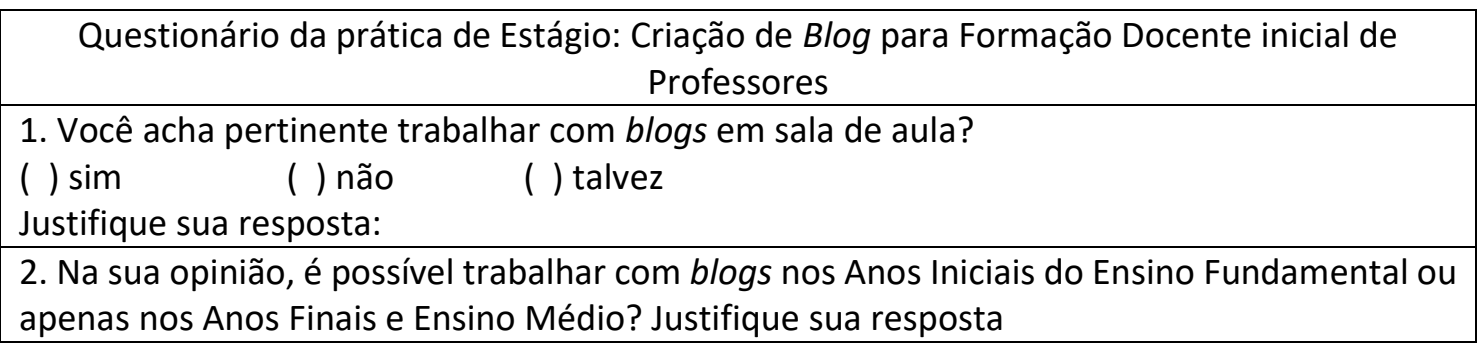

Fonte: As autoras (2019).

A primeira questão, todos os discentes assinalaram que sim, considerando ser pertinente o trabalho com os blogs em sala de aula e como justificativa, destacaram:

A18: O blog é uma ferramenta importante na introdução das tecnologias na escola, permite que os alunos produzam conteúdos que vão além da sala de aula, além de ser divertido e diferentes, ajuda na construção da leitura e da escrita.

A16: Vivemos em um mundo globalizado, onde os alunos estão inseridos diariamente no contexto tecnológico. Por isso, é importante trabalhar com esse método também em sala, utilizando da tecnologia e inclusive dos blogs como estratégia de ensino.

A01: Por se tratar de uma tecnologia digital, emergente nos dias de hoje, torna a aprendizagem mais prática e interessante para os alunos que, por sua vez, estarão motivados e inseridos nesse contexto. Dessa forma, haverá maior participação por parte do educando.

A35: Sim, porque os blogs são mais uma ferramenta que os professores podem usar a favor da educação e do aprendizado em sala de aula, e como a tecnologia tem avançado cada vez mais e nossos alunos tem cada vez mais acesso a isso se torna indispensável esse tipo de informação e conhecimento aos professores.

Por meio dos relatos dos acadêmicos, é possível verificar novos olhares para o uso da ferramenta blog no ensino como recurso e estratégia pedagógica e como produtores de mensagem. Os participantes persistiram "na função expressiva e representativa da comunicação" (BARDIN, 2016, p.165), para afirmar o pensamento próprio e a representação da mensagem.

Na segunda questão, tem-se a divisão das respostas em dois grupos, o primeiro em que reforça como positivo a utilização da ferramenta blog e o segundo grupo que faz algumas ressalvas para que a sua utilização aconteça no processo de ensino. As respostas destacam que: 
A19: É possivel trabalhar com blogs nos anos iniciais do ensino fundamental, visto que as crianças já nasceram no mundo tecnológico, cabe ao professor estar disposto e saber como trabalhar com as crianças.

A02: Sim. Porque antes de iniciarem o primeiro ano do ensino fundamental as crianças já tem acesso a internet, por meio dos celulares e tablets. Portanto, a utilização de blogs como ferramenta no ensino-aprendizagem, desperta a curiosidade dos alunos e torna o ensino mais prazeroso. A educação tradicional já não é mais suficiente, uma vez que, crianças e jovens estão envolvidos com as tecnologias de informação

A03: Pode ser trabalhado desde o ensino fundamental, afinal a maioria das crianças dessa geração já possuem contato com as tecnologias virtuais. Uma ótima ideia é a construção do portfólio virtual, onde os alunos podem interagir na plataforma.

A01: É possivel. Utilizando blogs com os alunos dos anos iniciais do ensino fundamental, todos poderão treinar a leitura e a escrita em um meio que já nasceram, as tecnologias digitais. Também incentivarão com apreço seus colegas, suas atividades e suas criações. Outro recurso presente nos blogs e que potencializa a aprendizagem dos alunos são os jogos, ferramentas pedagógicas de enorme abrangência.

É possível perceber a partir dos comentários que ocorre o reforço positivo frente a utilização do blog como ferramenta e estratégia potencializado no processo de ensinoaprendizagem. Essa mensagem apresentada pelos discentes, apresenta-se como Bardin (2016) relata sobre a importância de toda a mensagem, constituindo-se como ponto de partida de discussões e reflexões futuras.

O segundo grupo que faz algumas ressalvas para que a utilização do blog aconteça no processo de ensino, apresenta mensagens de cunho afirmativo, outra de dúvida, porém, as ressalvas que apresentam, de acordo com Bardin (2016), partem para a significação que carregam consigo, como o código e a significação, ambas ligadas a análise de conteúdo da mensagem como um todo, o código, que revela aquilo que não se manifesta claramente, já a significação está ligada aos significados que a mensagem fornece.

Destacam-se as seguintes respostas:

A12: Com os alunos do ensino fundamental dos anos finais e ensino médio acredito que seja mais fácil a interação dos alunos com o blog, já com os alunos do fundamental inicial as postagens podem ser feitas pelos professores e visitas ao blog feitas pelos pais.

A09: nos anos iniciais, é mais difícil de conseguir pela maturidade e tamanho das turmas, e no ensino público a disponibilidade de tempo e computadores é 
precária. Nos anos finais e o ensino médio se bem planejado e organizado pode ser possivel.

A24: É possivel sim trabalhar com blogs nos anos iniciais do ensino fundamental, pois esses contam com a tecnologia é muito importante, é uma 'timo ferramenta para pesquisa, porém, para a construção de um deve ser aplicado nos anos finais do fundamental e no ensino médio ou com o auxílio de um professor nos anos iniciais, uma espécie de diário da turma.

A18: É possivel, porém depende muito do professor, pois este deverá dar todo o auxílio e suporte para os alunos o que tomará bastante tempo. Uma opção seria o professor criar um blog juntamente com os alunos, o blog poderia ter um tema específico, artes por exemplo, e lá o professor poderia postar as produções dos alunos e a rotina de sala de aula, sempre mostrando aos alunos como está o andamento do blog, o professor pode ainda portar vídeos e fala dos alunos sobre essa experiência. Seria um trabalho em conjunto, um planejamento que vai além de uma aula, então é possível sim trabalhar com blogs nos anos iniciais.

A significação dessas respostas carrega um lócus de observação importante. Observa-se que, ao contrário do que Moran (2013) fala sobre os alunos tornarem-se o centro do processo, os futuros discentes veem o uso das tecnologias com certa precaução, em que o professor terá o controle maior, com pouca participação dos alunos. Outros retratam sobre a precarização do ensino público, como a grande dificuldade de ações pedagógicas desse cunho sejam exploradas com as crianças menores.

É preciso observar a infraestrutura escolar e conhecer os alunos, considerando como é a sua vivência em casa para planejar atividades com a utilização de ferramentas pedagógicas, pois, para uma aprendizagem colaborativa, como afirma Behrens (2013, p.85) é a partir dela que "enfatiza-se ter prazer em descobrir, em investigar, em ter curiosidade, em construir e reconstruir o conhecimento". Portanto, reconhecer a importância da relação entre professor e alunos como sujeitos que possam interagir e aprender em conjunto deve ser considerada.

\section{Considerações finais}

As discussões a respeito do uso das Tecnologias Digitais da Informação e Comunicação TDIC no espaço escolar tem ganhado destaque nos últimos anos, em virtude de sua expansão e facilidade de acesso de grande parte da população. Por mais que elas já estejam presentes a muito tempo e de diferentes formas no cotidiano das pessoas, torna-se relevante aprofundar as reflexões sobre como elas podem potencializar o processo de ensino-aprendizagem. 
Nesse contexto, este estudo teve como objetivo apresentar a possibilidade de se utilizar o blog como ferramenta didática, por meio do estágio de docência no Ensino Superior, unindo a prática de estágio de docência com a disciplina de Educação e Tecnologias. Desse modo, foi possível verificar que há necessidade de muitas discussões a respeito da implementação e do uso das ferramentas tecnológicas, e como aliá-las em um processo de enriquecimento do ensino, levando em consideração as adversidades dos diferentes espaços educativos, indo desde a Educação Básica até o Ensino Superior.

Os acadêmicos que participaram do estudo apresentaram interesse em explorar a ferramenta, uma vez que se mudou a impressão de que ela estaria ultrapassada e que não teria como utiliza-la como recurso pedagógico em sala de aula. Ao explorar as possibilidades do blog, foi possível corroborar com a ideia que o uso dos softwares e aplicativos possibilita uma visão de ensino mais plural e significativo, onde a participação dos alunos de modo ativo é um grande aliado.

Tais ferramentas tecnológicas educacionais vêm ganhando destaque, sobretudo pelo grande aumento da utilização pessoal dos recursos digitais e a sua incorporação no ambiente educativo vem ocorrendo de modo gradual. Deve-se pensar que essa inserção deverá vir acompanhada de um planejamento, a fim de atender as necessidades dos sujeitos inseridos no ambiente e em consonância com o currículo formativo, de modo a incorporar e potencializar o processo de ensino-aprendizagem

\section{Referências}

BACICH, L.; MORAN, J. (orgs.). Metodologias ativas para uma educação inovadora: uma abordagem teórico-prática. Porto Alegre: Penso, 2018.

BARDIN, L. Análise de conteúdo. Trad. Luís A. Reto e Augusto Pinheiro. São Paulo: Edições 70, 2016.

BEHRENS, M. A. Projetos de aprendizagem colaborativa num paradigma emergente. In: MORAN, J. M.; MASETTO, M. T.; BEHRENS, M. A. Novas tecnologias e mediação pedagógica. 21. ed. Campinas: Papirus, 2013, p.73-140. (Coleção Papirus Educação).

BRASIL. Coordenação de Aperfeiçoamento de Pessoal de Nível Superior (CAPES). Portaria no. 76, de 14 de abril de 2010. Disponível em: 
https://www.capes.gov.br/images/stories/download/legislacao/Portaria_076_RegulamentoDS. pdf. Acesso em 06 abri. 2020.

CHIOFI, L. C.; OLIVEIRA, M. R. F. O uso das tecnologias educacionais como ferramenta didática no processo de ensino e aprendizagem. In: JORNADA DE DIDÁTICA, DESAFIOS PARA A DOCÊNCIA, 3.; SEMINÁRIO DE PESQUISA DO CEMAD, 2., 2014. Anais [...]. Universidade Estadual de Londrina - UEL. 2014, p.329-337. Disponível em:

http://www.uel.br/eventos/jornadadidatica/pages/arquivos/III\%20Jornada\%20de\%20Didatica \%20\%20Desafios\%20para\%20a\%20Docencia\%20e\%20II\%20Seminario\%20de\%20Pesquisa\%20d O\%20CEMAD/O\%20USO\%20DAS\%20TECNOLOGIAS\%20EDUCACIONAIS\%20COMO\%20FERRAM ENTA.pdf. Acesso em: 29 mar. 2020.

GOMES, J. M. Blogs: um recurso e uma estratégia pedagógica. In: SIMPÓSIO INTERNACIONAL DE INFORMÁTICA EDUCATIVA, 7., 2005. Anais [...]. Leiria, Portugual, 16-18 novembro de 2005, p.311-315. Disponível em:https://repositorium.sdum.uminho.pt/bitstream/1822/4499/1/Blogs-final.pdf. Acesso em: 06 abr. 2020.

MORAN, J. M. Ensino e aprendizagem inovadores com apoio de tecnologias. In: MORAN, J. M.; MASETTO, M. T.; BEHRENS, M. A. Novas tecnologias e mediação pedagógica. 21. ed. Campinas: Papirus, 2013, p.11-72. (Coleção Papirus Educação).

PIMENTA, S. G.; LIMA, M. S. L. Estágio e docência. São Paulo: Cortez, 2018. (Coleção Docência em Formação: Ensino Superior).

PRIMO, A. Ferramentas de interação em ambientes educacionais mediados por computador. Educação, v.26, n.44, p.127-149, 2001. Disponível em: http://www.ufrgs.br/limc/PDFs/ferramentas_interacao.pdf. Acesso em: 29 mar. 2020.

SUNAGA, A.; CARVALHO, C. S. As tecnologias digitais no ensino híbrido. In: BACICH, L.; NETO, A. T.; TREVISANI, F. M. (orgs.). Ensino híbrido: personalização e tecnologias na educação. Porto Alegre: Penso, 2015, p.141-154.

TEIXEIRA, A. C.; BRANDÃO, E. J. R. Software educacional: o difícil começo. Revista Renote Novas Tecnologias na Educação; CINTED-UFRGS. v.1, v.1, fev. 2003. Disponível em: https://www.seer.ufrgs.br/renote/article/view/13629/7699. Acesso em: 28 mar. 2020

UNICENTRO. Plano de ensino Educação e Tecnologias. 2019. Disponível em:<https://www3.unicentro.br/proen/cursos/matrizes-curriculares/\#15374846322324b76e08b-0c47>. Acesso em 15 mar. 2020. 


\section{AGRADECIMENTOS}

À Coordenação de Aperfeiçoamento de Pessoal de Nível Superior (CAPES) pela concessão da bolsa de estudos.

Recebido em maio 2020.

Aprovado em janeiro 2021. 